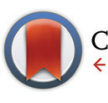

CrossMark \&lick for updates

Cite this: Polym. Chem., 2015, 6 , 3781

Received 17th October 2014, Accepted 29th March 2015

DOI: $10.1039 / c 4 p y 01418 a$

www.rsc.org/polymers

\title{
Synthesis of poly(spirosilabifluorene) copolymers and their improved stability in blue emitting polymer LEDs over non-spiro analogs $\uparrow$
}

\author{
Jeffrey J. McDowell, Dong Gao, Dwight S. Seferos and Geoffrey Ozin*
}

\begin{abstract}
We report herein a unique deep blue emitting copolymer, poly(3,6-dimethoxy-9.9'-dihexylsilafluoreneco-3.6-dimethoxy-2', 3',6',7'-tetrahexyloxy-9,9-spiro-9-silabifluorene) (PHSSF-co-PDHSF), which exhibits brilliant solid state blue luminescence, high quantum efficiency, excellent solubility and thermal stability. We have found that using PHSSF-CO-PDHSF copolymers with large volume fractions of spirosilabifluorene as the emissive layer in OLEDs correlates to more stable EL intensity and have improved lifetimes over non-spiro poly(silafluorene) devices. The HSSF monomer is prepared via a two-part procedure, with each part resulting in one of two biphenyl segments which combines in a final cyclization step involving tetrachlorosilane. One segment possesses two bromide groups necessary for the polymerization. We utilized an efficient nickel catalyzed polymerization based on diarylmagnesate monomers to create PHSSF-COPDHSF in good yield with number average molecular weights exceeding $50 \mathrm{~kg} \mathrm{~mol}^{-1}$ with a PDI $=1.8$. The polymerization was complete in less than $30 \mathrm{~min}$. For PHSSF-CO-PDHSF OLED devices, the maximum irradiance of the device was $40 \mathrm{~W} \mathrm{~m}^{-2}$ at a current density of $60 \mathrm{~mA} \mathrm{~cm} \mathrm{~cm}^{-2}$ and EL maximum centered at $410 \mathrm{~nm}$. The maximum device external quantum efficiency was $2.9 \%$ when operating at $38 \mathrm{~mA} \mathrm{~cm}{ }^{-2}$. To measure OLED stability, we monitored normalized EL intensity for both PHSSF-COPDHSF and PDHSF devices. Over the course of $10 \mathrm{~h}$, the EL intensity of the PDHSF device drops $20 \%$ more than the PHSSF-CO-PDHSF device when operating at $6 \mathrm{~mA} \mathrm{~cm}^{-2}$
\end{abstract}

\section{Introduction}

Integrating nonplanar "spiro" compounds ${ }^{1-22}$ into organic electronics shows promise for improving properties which are important for the efficient operation of devices such as organic light-emitting diodes (OLEDs), ${ }^{5-9}$ organic phototransistors (OPTs),${ }^{10,11}$ organic solid-state lasers (OSSLs), ${ }^{12-15}$ as well as organic thin film transistors (OTFTs). ${ }^{16,17}$ Such properties include morphological, thermal and chemical stability, superior isolation of emitting centers and hence enhanced photo/electroluminescent quantum efficiencies, better solubility and improved solution processability. ${ }^{18-22}$ Compounds which are considered "spiro" consist of two orthogonally arranged subsections centered on a tetravalent atom. There are many examples of symmetric as well as asymmetric spiro compounds in the literature, many common examples are spirobifluorenes (SF) derivatives. ${ }^{23-27}$ SFs are rigid 3D structures due to the lack of rotational freedom of orthogonal fluorene subunits, the molecular structure of spirobifluorenes effectively

Department of Chemistry, University of Toronto, 80 St. George Street, Toronto, ON M5S 3H6, Canada.E-mail: gozin@chem.utoronto.ca

$\dagger$ Electronic supplementary information (ESI) available: Complete ${ }^{1} \mathrm{H},{ }^{29} \mathrm{Si}$ and

${ }^{13} \mathrm{C}$ NMR spectra and polymer CV and GPC data. See DOI: $10.1039 / \mathrm{c} 4$ py01418a disrupts regular crystalline packing and results in films which have solution like photophyiscal properties. ${ }^{28-30}$ Consequently, SFs are an increasing important class of compound used in the design of new solid state chromophores with improved performance over simpler fluorene derivatives which show a higher tendency to crystallize and hence exhibit reduced PL efficiency. ${ }^{31,32}$ The appealing electronic and optical properties of other SF derivatives, including spiro-MeOTAD, has prompted their use in solar energy conversion as a charge transport material in, for example, dye sensitized solar cells. $^{33,34}$ The silicon analogs of SFs, spirosilabifluorenes (SSFs), have unique characteristics which distinguish them as subsets of the newly explored class of compounds called siloles. ${ }^{35-41}$ Siloles, as well as silafluorenes and spirosilabifluorenes, are becoming increasingly popular components in organic electronics due to their brilliant solid state blue luminescence and superior electron conductivity. ${ }^{42-46}$ The higher electron affinity and conductivity, which is particularly promising for OLEDs, originates from $\sigma^{*}-\pi^{*}$ conjugation between the $\sigma^{*}$ antibonding orbital of the exocyclic Si-C bond and the $\pi^{*}$ antibonding orbital of the butadiene fragment. ${ }^{47}$

Evidence for this phenomenon is obtained by measuring atypical bathochromic shifts in silole absorption spectrum and comparing results to corresponding carbon analogues. ${ }^{48}$ 
Kafafi et al. have reported a series of asymmetrically aryl-substituted 9,9'-spiro-9-silabifluorene derivatives which were prepared via the cyclization of the 2,2'-dilithiobiphenyls with silicon tetrachloride. ${ }^{48}$ These materials form amorphous films which are both transparent and stable due to a relatively high glass transition temperatures $\left(T_{\mathrm{g}}=203-228{ }^{\circ} \mathrm{C}\right)$. Solid state films of their materials were reported to have an intense violetblue emission $\left(\lambda_{\mathrm{em}}=398-415 \mathrm{~nm}\right)$ with high absolute photoluminescence quantum yields of $30-55 \%$. For many siloles, high PL efficiency can be attributed to a phenomenon known as aggregation induced emission (AIE). ${ }^{49}$ AIE compounds have significant potential as gain medium in solid state organic lasers in addition to light-emitting materials in OLEDs. In the latter case, SSFs have already shown impressive performance with OLED electroluminescence external quantum efficiencies as high as $\eta_{\text {eff }}=4.8 \%$ (at $10 \mathrm{~mA} \mathrm{~cm}{ }^{-2}$ ). ${ }^{50}$ Many low molecular weight siloles, however, crystallize readily, contributing to device degradation when these materials are incorporated in OLED structures. ${ }^{51}$ In an attempt to prevent this issue, we have prepared a unique deep blue emitting copolymer, poly(3,6dimethoxy-9.9'-dihexylsilafluorene-co-3.6-dimethoxy-2', $3^{\prime}, 6^{\prime}, 7^{\prime}$ tetrahexyloxy-9,9-spiro-9-silabifluorene) (PDHSF-co-PHSSF), with a spirosilabifluorene repeat unit (10), which we expected to exhibit high glass transition temperatures, improved solidstate PL quantum yields and have superior OLED performance. As we will later demonstrate, a large volume fraction of spirosilabifluorene leads to EL intensities of working OLEDs being measurably more stable with improved lifetimes over nonspiro poly(silafluorenes) devices.

\section{Results and discussion}

Fig. 1e illustrates the synthetic steps taken to create our spirosilabifluorene monomer. To the best of our knowledge, there has been no prior attempt to polymerize SSFs and hence no polymer LEDs have been constructed using PSSFs. The synthesis is two-part, each resulting in a segment (referred to as segment A and B) which combines in a final cyclization step involving tetrachlorosilane. Segment A possesses two bromide groups necessary for the polymerization, details of which will be discussed below. Its synthesis begins with commercially available $o$-dianisidine (1) starting material which is easily converted to (2) by the reaction of an intermediate bis(diazonium) salt with $\mathrm{CuBr}$ (the latter is produced in situ by the oxidation of (1) by $\mathrm{NaNO}_{2}$ ). Iodination of (2) is directed at carbons C5 and $\mathrm{C}^{\prime}$ ' by the electron donating methoxy groups at C3 and C3'. Yields of both reactions are high, averaging $85 \%$ for the Sandmeyer bromination deamination and $80 \%$ for the iodination.

Notable features of segment B include four hexyloxy groups installed to increase solubility of the monomer and resultant polymer. Segment B is also the product of several high yielding steps beginning with catechol (4). Both hydroxyl groups are converted to hexyloxy following reflux with 1-bromohexanes in DMF. Following purification, (5) undergoes a single iodination
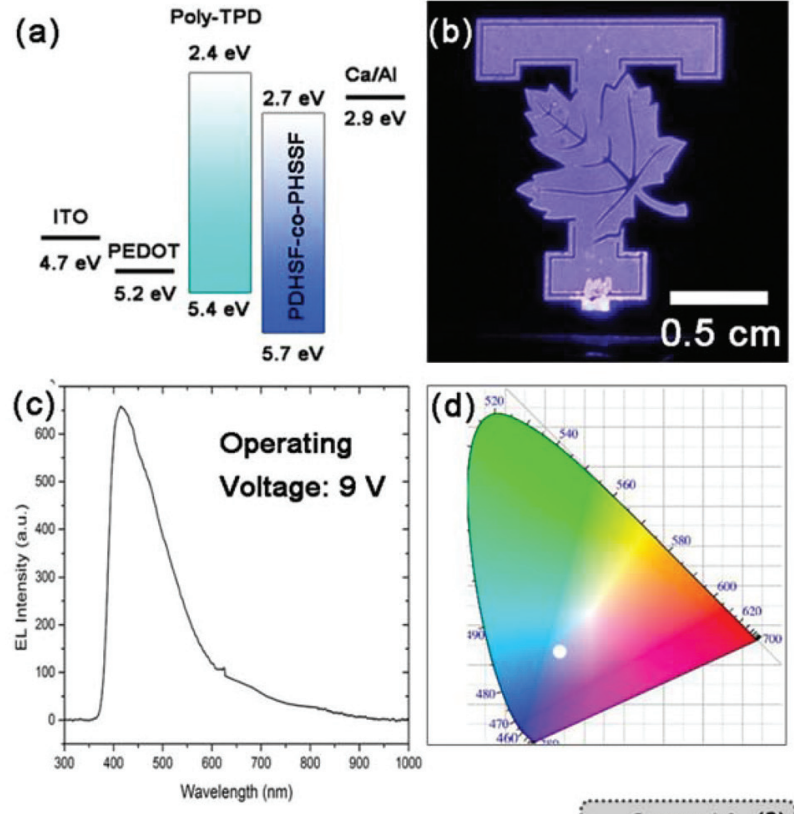

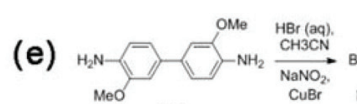

(1)

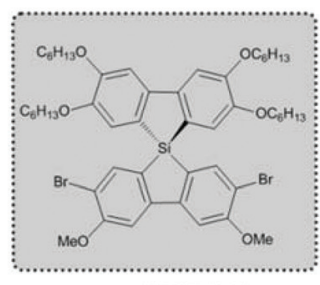

HSSF (10)

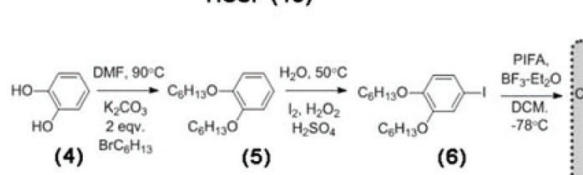

(4)

(5)

(6)
(2)
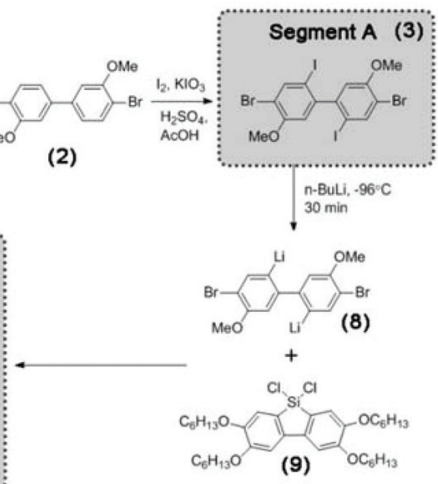

(i) n-BuLi, $-78^{\circ} \mathrm{C}$ $\mathrm{SiCl}_{4}$
Fig. 1 (a) Illustration of PLED architecture indicating respective energy levels of layers. (b) Photograph of a PHSSF-co-PDHSF device under $9 \mathrm{~V}$ operation. (c) EL spectrum of device featured in (a). (d) CIE colour map with white circle indicating the position of PHSSF-Co-PDHSF PLED emission. (e) Scheme illustrating the synthesis of both segments $A$ and $B$ which are reacted with $\mathrm{SiCl}_{4}$ to form the final spiro-bisilafluorene monomer (10).

after being stirred in an aqueous solution (acidified with $\mathrm{H}_{2} \mathrm{SO}_{4}$ ) with a slight access of $\mathrm{I}_{2}$ and $\mathrm{H}_{2} \mathrm{O}_{2}$ oxidant. 1-Iodo-3,4dihexyloxybenzene (6) was collected as a pure liquid, the last fraction of a vacuum distillation which efficiently separates it from non-iodonated starting materials. To obtain the biphenyl (7), a unique aryl coupling procedure was used involving the reaction of (6) with the hypervalent iodine complex phenyliodine bis(trifluoroacetate), PIFA, in the presence of a yield improving additive $\mathrm{BF}_{3}-\mathrm{Et}_{2} \mathrm{O}$. The mechanism by which aryl 
coupling occurs has been the subject of numerous reviews. ${ }^{53,54}$ This exothermic reaction is performed whilst cooling with a dry ice/acetone bath to control the rate, which is high despite the low temperature. Product is formed readily by the time the reaction warms to room temperature. Pure (7) is obtained by crystallization at low temperatures from hexanes. The product forms white, blocky crystals which readily dissolve in organic solvents. Lithiation is performed at low temperatures using an acetone/dry ice bath by dissolving (7) in THF and adding two equivalence of $n$-butyl lithium. The metathesis is quantitative within a few minutes.

The first of two cyclization reactions begins with a duel substitution reaction involving lithiated (7) and $\mathrm{SiCl}_{4}$ to form two $\mathrm{LiCl}$ and the ring-closed dichlorosilafluorene (9). Because the rate of substitution is quiet high, the order of addition is crucial to avoiding large amounts of unwanted symmetric spirosilabifluorenes. While maintaining a low temperature for both solutions, the soluble dilithiated (7) is added to a separate solution of $\mathrm{SiCl}_{4}$ in THF. The reaction is complete by the time the solution warms to room temperature. Solvent is removed in vacuo from the moisture sensitive (9) and the crude product residue is redissolved in dry hexanes and cooled to precipitate out less soluble by-products. Removal of hexanes yields the pure dichlorosilafluorene segment and concentrated THF solutions of this compound can be stored for long periods of time with refrigeration. ${ }^{29} \mathrm{Si}$ NMR of (9) shows a single peak at $5.8 \mathrm{ppm}$, confirming the purity of the intermediate (see ESI $\dagger$ ).

To complete the second cyclization and generate the final spirosilabifluorene monomer, segment A is reacted with two equivalence of $n$-BuLi in an analogous manner to the reaction with (7). However, it is necessary to maintain the temperature of this reaction at $-100{ }^{\circ} \mathrm{C}$ (using a nitrogen/MeOH slush bath) throughout the lithiation step to ensure selectivity for iodide while both bromide groups remain unreacted. A concentrated solution of the dichlorosilafluorene (9) in THF equalling one equivalence with respect to (8), is added and the final product is purified by crystallization from hexanes. Fig. 2 shows the ${ }^{1} \mathrm{H}$ NMR of 2.7-dibromo-3.6-dimethoxy-2',3',6', $7^{\prime}$ tetrahexyloxy-9,9-spiro-9-silabifluorene (10). Additionally, ${ }^{29} \mathrm{Si}$ NMR of this compound consists of a single resonance peak at $-8.6 \mathrm{ppm}$ belonging to the pure product. Complete characterization of (10) can be found in the Experimental section and ESI. $\dagger$

Prior to polymerization, the dibromide HSSF premonomer (10) converted to its respective diarylmagnesates by Grignard metathesis. The highest rate of conversion was obtained when using a mixed solvent system consisting of $30 \%$ 1,4-dioxane in tetrahydrofuran. Within $2 \mathrm{~h},>95 \%$ of HSSF was converted to bis(bromo-3,6-dimethoxy-2', 3',6', $7^{\prime}$-tetrahexyloxy-9,9-spiro-9silabifluorene)magnesate (12). In a separate reaction, 2,7dibromo-3,6-dimethoxy-9,9-dihexylsilafluorene was converted to its respective diarylmagnesate (11) under identical conditions. In both reactions, formation of an insoluble $\mathrm{MgCl}_{2}^{-}$ dioxane adduct is obvious from the precipitation of a fine white solid within a few seconds of adding iPrMgCl-LiCl.

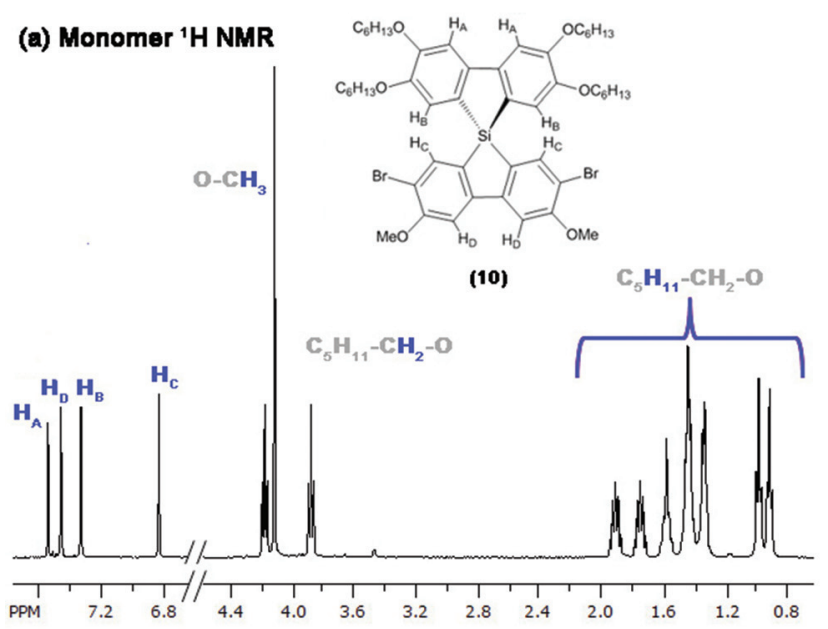

(b) Polymer ${ }^{1} \mathrm{H}$ NMR

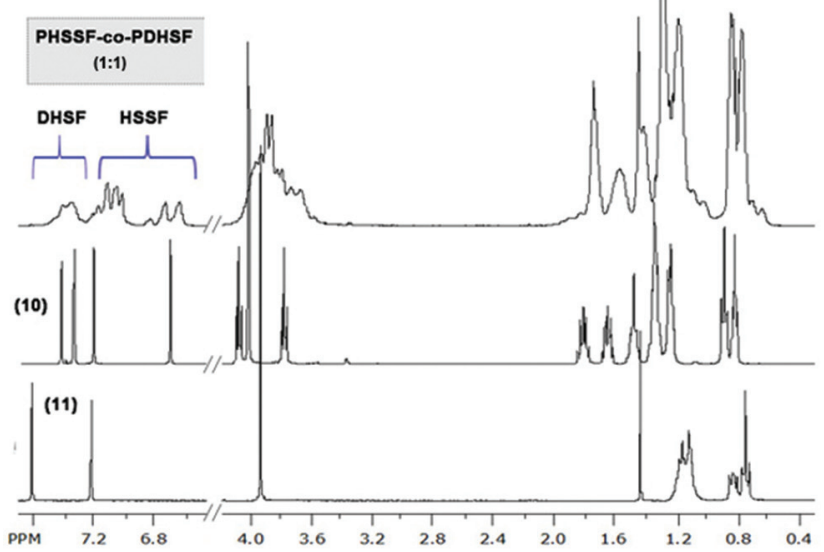

Fig. 2 (a) ${ }^{1} \mathrm{H}$ NMR of monomer (10) (purified by crystallization from hexanes) and assignment of peaks. (b) ${ }^{1} \mathrm{H}$ NMR of copolymer PHSSF-coPDHSF as well as the spectra of each monomer (for comparison). Broad aromatic peaks between 7.4-7.6 ppm belong to DHSF repeat units (as reported previously ${ }^{52}$ ). Integration of this broad set of peaks with respect to the remaining collection of four HSSF peaks gives an estimate of $1: 1$ DHSF to HSSF repeat units (Fig. S1.9.0 in ESI †).

We utilized an efficient nickel catalyzed polymerization based on diarylmagnesate monomers to create copolymers of (11) and (12) with roughly half of the repeat units derived from (11) (as determined by integration of respective aromatic ${ }^{1} \mathrm{H}$ NMR peaks and peaks of both monomer Si peaks in the ${ }^{29} \mathrm{Si}$ HMBC, see ESI Fig. S1.9.0-S1.9.2†). PHSSF-co-PDHSF (13) was produced in good yield with number average molecular weights exceeding $50 \mathrm{~kg} \mathrm{~mol}^{-1}$ with a PDI $=1.8$ (similar molecular weights were obtained for the DHSF homopolymer (52 kg mol ${ }^{-1}$; PDI $=1.7$, see ESI S2.1.0-S2.2.0 $\dagger$ ). The polymerization was complete in less than $30 \mathrm{~min}$ and polymerization was quenched by adding $\mathrm{HCl}$ followed by precipitation in methanol. Excess monomer and oligomers were removed by subsequent soxhlet extraction with EtOH over a period of 5-6 h. Fig. 3a and b illustrates the reaction conditions used in the polymerization. Fig. $2 \mathrm{~b}$ shows a representative ${ }^{1} \mathrm{H}$ NMR of the purified polymer. 
(a) Grignard Metathesis

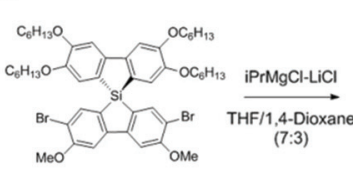

(10)

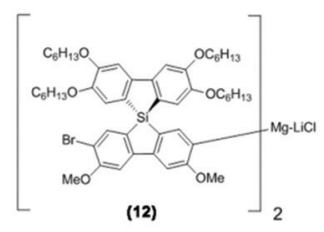

\section{(b) Polymerization}

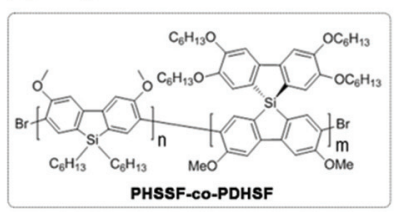

(c) Abs./PL/EL Characterization

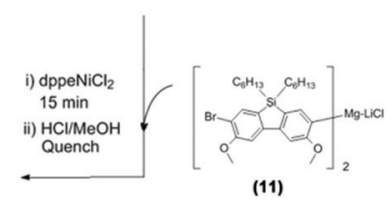

(11)

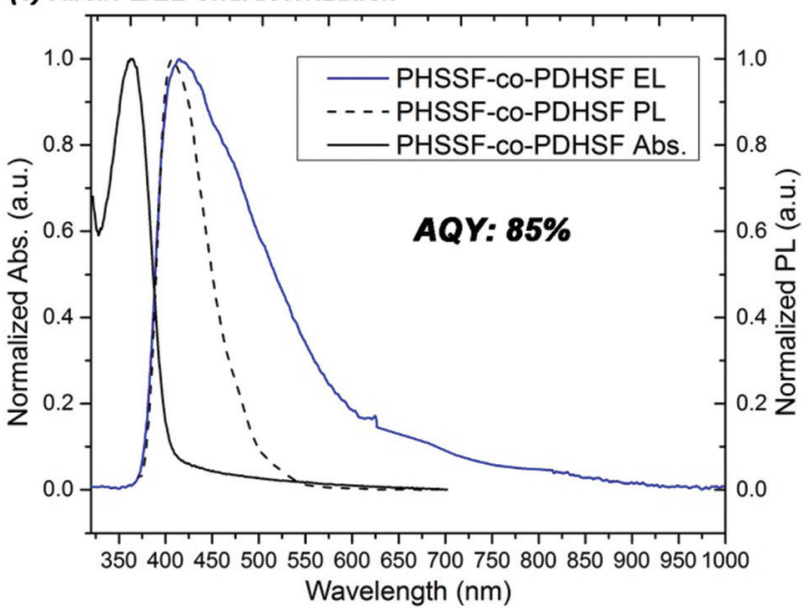

Fig. 3 (a) Scheme illustrating the conversion of (10) to (12) via Grignard metathesis in a mixed THF-1,4-dioxane $(7: 3)$ solvent and the subsequent copolymerization (b) of (11) and (12) to yield PHSSF-co-PDHSF. (c) Characteristic solid state absorption and PL spectra of PHSSF-coPDHSF plotted with comparison to EL.

Initial thermal analysis of the copolymer using TGA/DSC indicates the material is stable under nitrogen up to a temperature of $350{ }^{\circ} \mathrm{C}$, Fig. 4. Morphologically, there were no obvious phase transitions occurring within the temperature region of $25-250{ }^{\circ} \mathrm{C}$ over numerous cycles. PSFs are known for their thermal stability, and our initial findings seem to indicate that adding HSSF into the polymer backbone does nothing if not improve this quality. ${ }^{55-57}$

The HOMO energy of the PHSSF-Co-PDHSF copolymer was determined using cyclic voltammetry and the bandgap was determined from the solid-state absorption onset (CV can be found in ESI $\dagger$ and absorption spectrum is shown Fig. 3c). It was found that HOMO/LUMO energy levels (5.7 eV and $2.7 \mathrm{eV}$ respectively) are identical to those reported earlier by our group for similar polysilafluorene. ${ }^{52}$

Light emitting devices were constructed in a $\mathrm{N}_{2}$ filled glovebox on $\mathrm{O}_{2}$ plasma treated ITO on glass. We employed a simple trilayer design using PEDOT:PSS as the hole injection layer $(\sim 10 \mathrm{~nm})$ as well as a thin hole transport layer consisting of poly-TPD $(\sim 20 \mathrm{~nm})$. A $100 \mathrm{~nm}$ emissive layer consisting of

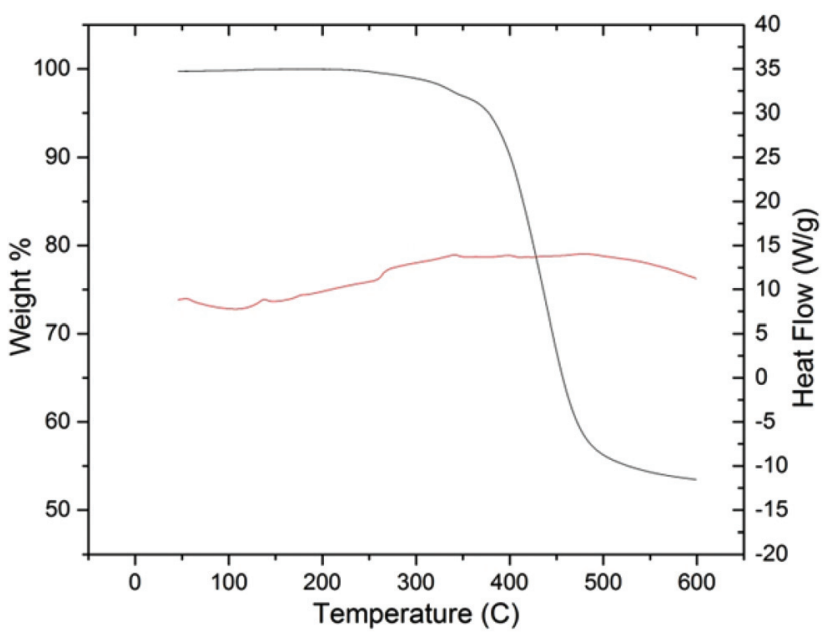

Fig. 4 TGA/DSC of PHSSF-Co-PDHSF over the temperature range 25-200 ${ }^{\circ} \mathrm{C}$. No $T_{\mathrm{g}}$ or $T_{\mathrm{m}}$ phase changes occur over multiple cycles.

PHSSF-co-PDHSF was deposited by spin casting from a $10 \mathrm{mg}$ $\mathrm{mL}^{-1}$ polymer solution in toluene. A Ca cathode, which best matches the copolymer LUMO energy of $2.7 \mathrm{eV}$, was found to yield the best performing devices. Fig. 1a illustrates the device architecture and energy levels of the respective layers. A photograph of a functioning device operating at $9 \mathrm{~V}$ is shown in Fig. 1b. A respective electroluminescence spectrum is shown in Fig. 1c. The EL peak maximum is nearly identical to the thin film PL spectra at $\sim 410 \mathrm{~nm}$. However, the FWHM of the EL emission is noticeably larger than the solid-state PL, Fig. 3c. Fig. 1d shows the location of the device's blue-violet emission on the CIE colour map with coordinates of $x=0.246$ and $y=0.237$.

Performance data obtained from devices with PHSSF-coPDHSF and PDHSF emissive layers is presented in Fig. 5. PDHSF OLEDs were created for the purpose of comparison and to establish the impact of spirosilabifluorene on performance. The OLEDs tested both have $0.25 \mathrm{~cm}^{2}$ emissive areas. Referring to the $I-V$ curve, we observe the turn on voltage to be roughly $5 \mathrm{~V}$ in both devices. This is not surprising given the energy levels of both emissive materials are essentially identical. Both devices were operated up to $10 \mathrm{~V}$ and each reached a maximum current density of $\sim 65 \mathrm{~mA} \mathrm{~cm}^{-2}$. For the PHSSF-coPDHSF device, the maximum irradiance of the device was $40 \mathrm{~W} \mathrm{~m}^{-2}$ at a current density of $60 \mathrm{~mA} \mathrm{~cm}^{-2}$. The maximum efficiency of the device, in terms of EQE, was $2.9 \%$ when operating at $38 \mathrm{~mA} \mathrm{~cm}^{-2}$. Likewise, the PDHSF device operated at a maximum irradiance of $38 \mathrm{~W} \mathrm{~m}^{-2}$ at a current density of $45 \mathrm{~mA} \mathrm{~cm}^{-2}$. The maximum efficiency of the device was $2.5 \%$ when operating at $30 \mathrm{~mA} \mathrm{~cm}^{-2}$.

Over extended device operation times, however, a significant difference in performance emerges. Fig. 6 plots the averaged EL intensity for the different devices over a period of $10 \mathrm{~h}$ (the data set consists of six total devices, with three of each type). When operating with a current density of $6 \mathrm{~mA} \mathrm{~cm} \mathrm{~cm}^{-2}$, both device types show a gradual decline in EL intensity. 

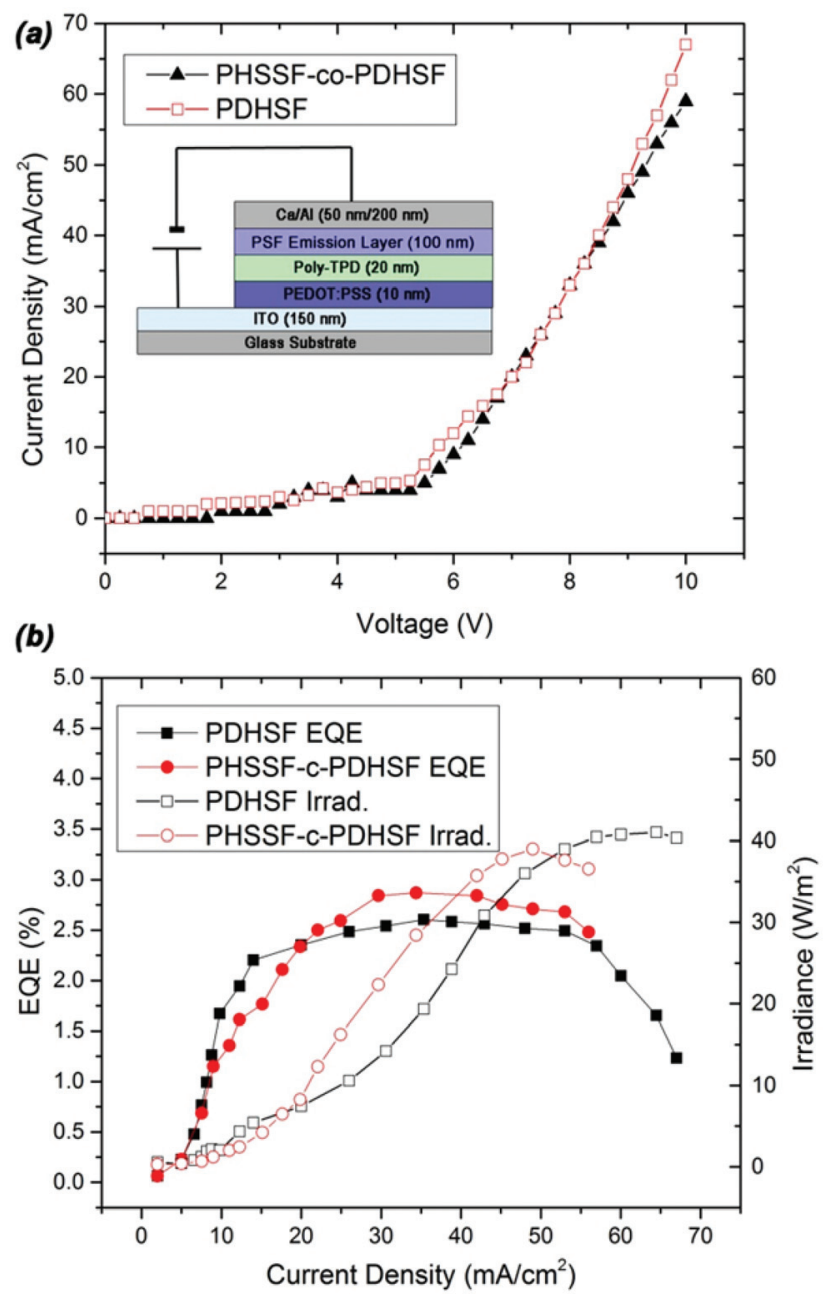

Fig. 5 (a) $I-V$ plots of both PHSSF-co-PDHSF and PDHSF devices. In both cases, device turn-on occurs at $\sim 5 \mathrm{~V}$. Light was collected using a calibrated integrating sphere coupled to a fibre spectrometer. (b) Plot of EQE and Irradiance as a function of current density of both PHSSF-coPDHSF and PDHSF devices. Note the maximum efficiency achieved was $2.9 \%$ at $38 \mathrm{~mA} \mathrm{~cm}^{-2}$ for PHSSF-Co-PDHSF and $2.5 \%$ at $30 \mathrm{~mA} \mathrm{~cm}^{-2}$ for PDHSF.

The slope of the PHSSF-co-PDHSF device, however, is noticeably less than the PDHSF device. We posit the reason for such a noticeable deviation is the spirosilabifluorene unit. The inclusion of this rigid 3D structure in the polymer backbone leads to reduced interaction between neighbouring chains, preventing the degenerative effects of crystallization and excimer formation resulting in an overall increase in electroluminescent yield over a longer time frame.

\section{Conclusions}

In future work, we intend to increase the number of copolymers produced by this method with the aim of producing stable blue, green and red emitters for light emitting technologies. It would also be of considerable interest to combine the

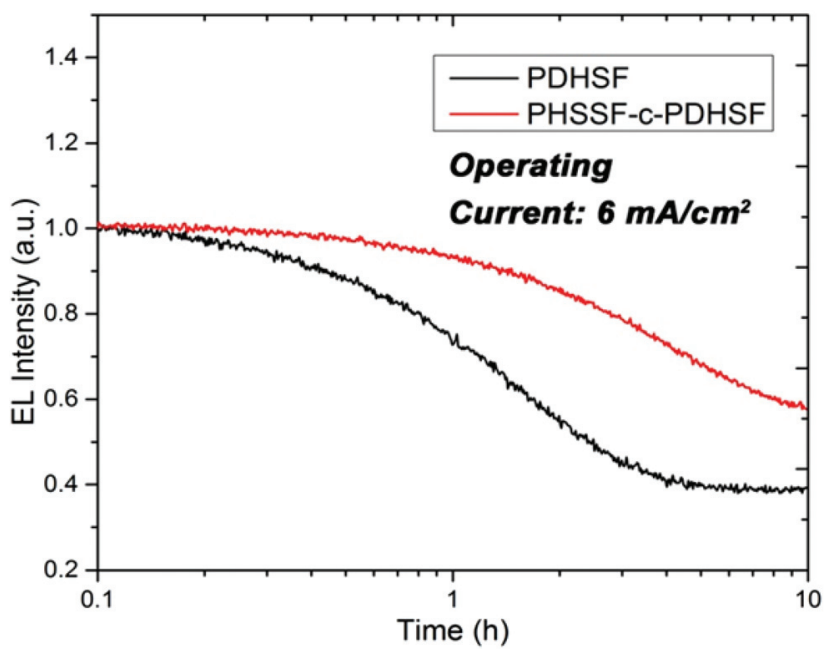

Fig. 6 Plot of the EL intensity for both PHSSF-co-PDHSF and PDHSF devices. Over the course of $10 \mathrm{~h}$, the EL intensity of the PDHSF device drops $20 \%$ more than the PHSSF-Co-PDHSF device.

promising performance of these copolymers with the additional functionality of photocrosslinkable versions of PSF which our group has previously reported on. ${ }^{58}$ Ultimately the goal is to develop longer lasting emitters which can be photolithographically patterned to allow for solution processed full colour thin-film displays driven by TFT backplanes as well combining multiple long lifetime polymer emitters to produce solution processed WOLEDs.

\section{Experimental}

All syntheses were performed under inert atmosphere using standard schlenk line or glovebox techniques unless otherwise stated. Chemicals were purchased from TCI America and Sigma Aldrich and used without need for further purification. Tetrahydrofuran and 1,4-dioxane were distilled over sodium/ benzophenone prior to use. Proton, carbon and silicon NMR were performed on a $400 \mathrm{MHz}$ Bruker Avance III Spectrometer. Solution and thin film absorption and photoluminescence spectra were recorded using a Perkin-Elmer 900 UV-Vis Spectrometer and a Perkin-Elmer LS-50B Luminescence Spectrophotometer. Polymer quantum efficiencies were calculated through the use of an integrating sphere using a focused $365 \mathrm{~nm}$ LED as the excitation source. ${ }^{59}$ Polymer molecular weights were measured with a Viscotek GPC calibrated with respect to polystyrene standards using THF as an eluent and column temperature of $35^{\circ} \mathrm{C}$. Cyclic voltammetry was performed on polymer samples in a solution of $100 \mathrm{mM}$ tetrabutylammonium hexafluorphosphate in dichloromethane (distilled from $\mathrm{CaH}_{2}$ under $\mathrm{N}_{2}$ prior to measurement). Potentials were measured using a Solartron 1278 potentiostat using platinum working and counter electrodes in addition to a $\mathrm{Ag} /$ $\mathrm{AgCl}$ pseudo reference electrode. Measurements were calibrated using ferrocene as an internal standard. Thermogravo- 
metric and calorimetric data was acquired using a TA Instruments SDT Q600 simultaneous TGA/DSC system operated under an inert $\mathrm{N}_{2}$ atmosphere. Poly(3,6-dimethoxy-9,9-dihexylsilafluorene) (PDHSF) was prepared using a previously published procedure. ${ }^{52}$

\section{HSSF monomer synthesis}

4,4'-Dibromo-3,3'-dimethoxy-1,1'-biphenyl (2). The synthesis of (2) is adapted from the Sandmeyer reaction outlined by Haung et al. ${ }^{60}$ o-dianisidine is oxidized to its diazonium salt and reacted with a bromide source to eliminate $\mathrm{N}_{2}$ and generate the appropriate aryl dibromide. $10.0 \mathrm{~g}$ (40 $\mathrm{mmol}) o$-dianisidine is combined with $40 \mathrm{~mL} 40 \% \mathrm{HBr}, 160 \mathrm{~mL} \mathrm{H}_{2} \mathrm{O}$ and $160 \mathrm{~mL}$ acetonitrile in a large three necked flask equipped with a thermometer, dropping funnel and efficient stirring. The majority of the starting material is dissolved in acetonitrile. The reaction is cooled to $0{ }^{\circ} \mathrm{C}$ an ice/salt bath, $7.2 \mathrm{~g}$ (104.4 mmol) sodium nitrite (dissolved in $14 \mathrm{~mL}$ water) is chilled and added dropwise to the reaction such that the temperature does not rise above $10^{\circ} \mathrm{C}$. Following addition, the reaction is stirred at reduced temperature for $30 \mathrm{~min}$. Meanwhile, freshly prepared $\mathrm{CuBr}$ is obtained by precipitation of $\mathrm{CuNO}_{3}$ and $\mathrm{NaBr}$ in water. ${ }^{61}$ The white precipitate is collected by filtration and dried in a vacuum oven prior to use. $13.0 \mathrm{~g}$ (90.6 mmol) $\mathrm{CuBr}$ is dissolved in $160 \mathrm{~mL} \mathrm{40 \%} \mathrm{HBr}$ (aqueous) and added to the thoroughly rinsed dropping funnel. Glass tubing is used to extend the stem of the dropping funnel below the surface of the solution to prevent side reaction with atmospheric $\mathrm{O}_{2} \cdot \mathrm{CuBr} / \mathrm{HBr}$ is added slowly, maintaining a temperature less than $10^{\circ} \mathrm{C}$, over the course of $1 \mathrm{~h}$. The solution is then allowed to warm to room temperature and is subsequently heated to reflux $\left(80^{\circ} \mathrm{C}\right)$ for $1 \mathrm{~h}$ until an insoluble white solid becomes apparent. The solution is then cooled and extracted with 250-300 mL chloroform, washed with $10 \mathrm{wt} \%$ $\mathrm{NaOH}$ and brine, and finally dried with $\mathrm{MgSO}_{4}$ before removing solvent by rotoevaporation. The crude, light brown powder is sufficiently pure to proceed to the next step. Yield is $13 \mathrm{~g}$ or 90\%. ${ }^{1} \mathrm{H}-\mathrm{NMR}\left(\mathrm{CD}_{2} \mathrm{Cl}_{2}, 400 \mathrm{MHz}\right)(\mathrm{ppm}): 7.53\left(\mathrm{H}_{\mathrm{B}}, \mathrm{d}, 2 \mathrm{H}\right)$, $6.96\left(\mathrm{H}_{\mathrm{A}}, \mathrm{s}, 2 \mathrm{H}\right), 6.95\left(\mathrm{H}_{\mathrm{C}}, \mathrm{dd}, 2 \mathrm{H}\right) 3.10\left(-\mathrm{OCH}_{3}, \mathrm{~s}, 6 \mathrm{H}\right)$ ${ }^{13} \mathrm{C}-\mathrm{NMR}\left(\mathrm{CD}_{2} \mathrm{Cl}_{2}, 400 \mathrm{MHz}\right)(\mathrm{ppm}): 156.19$ (C3), 141.35 (C1), 133.56 (C3), 120.59 (C6), 111.38 (C4), 110.87 (C2), 56.35 $\left(-\mathrm{OCH}_{3}\right)$. EI-MS $\left(\mathrm{M}^{+}\right)=369.9204 \mathrm{~m} / z$ (calc: 369.9213$)$.

4,4'-Dibromo-2,2'-diiodo-5,5'-dimethoxy-1,1'-biphenyl Selective iodination at the 2 and $2^{\prime}$ is directed by para substituted methoxy groups. $13.0 \mathrm{~g}(34.9 \mathrm{mmol})(2), 3.3 \mathrm{~g}$ $(15.4 \mathrm{mmol}) \mathrm{KIO}_{3}$ and $\left.9.6 \mathrm{~g}(38.0 \mathrm{mmol})\right) \mathrm{I}_{2}$ are added to a large three neck flask equipped with a reflux condenser. The starting material is dissolved in a mixture of $260 \mathrm{~mL}$ acetic acid and $26 \mathrm{~mL} 20 \mathrm{wt} \% \mathrm{H}_{2} \mathrm{SO}_{4}$. The solution is heated to $80{ }^{\circ} \mathrm{C}$ for $12 \mathrm{~h}$. Large amounts of insoluble product precipitate as the reaction proceeds. Once cooled to room temperature, an additional $250 \mathrm{~mL}$ of $\mathrm{H}_{2} \mathrm{O}$ is added to precipitate further product. The precipitate is collected by filtration, dried briefly under vacuum and redissolved in the minimum amount of $\mathrm{CHCl}_{3}(\sim 200 \mathrm{~mL})$. The solution is extracted with $10 \mathrm{wt} \%$ $\mathrm{NaOH}$, washed with brine, and finally dried with $\mathrm{MgSO}_{4}$ before removing the solvent by rotoevaporation. The crude product is then purified by recrystallization from boiling $95 \%$ ethanol ( $\sim 45 \mathrm{~mL}$ EtOH per $\mathrm{g}$ of crude product). The resulting brown needle like crystals are collected by filtration and rigorously dried in a vacuum oven prior to being used in the following step. The yield of purified product following the first recrystallization is $12.4 \mathrm{~g}$ or $56 \%$. Yield can be improved to $84 \%$ by concentrating the supernatant cooling to produce another crop of crystals. ${ }^{1} \mathrm{H}-\mathrm{NMR}\left(\mathrm{CD}_{2} \mathrm{Cl}_{2}, 400 \mathrm{MHz}\right)(\mathrm{ppm})$ : $7.98\left(\mathrm{H}_{\mathrm{B}}, \mathrm{s}, 2 \mathrm{H}\right), 6.66\left(\mathrm{H}_{\mathrm{A}}, \mathrm{s}, 2 \mathrm{H}\right), 3.81\left(-\mathrm{OCH}_{3}, \mathrm{~s}, 6 \mathrm{H}\right)$. ${ }^{13} \mathrm{C}-\mathrm{NMR}\left(\mathrm{CD}_{2} \mathrm{Cl}_{2}, 400 \mathrm{MHz}\right)(\mathrm{ppm}): 156.14$ (C5), 148.16 (C1), 142.08 (C3), 113.30 (C6), 112.45 (C4), 87.56 (C2), 56.49 $\left(-\mathrm{OCH}_{3}\right)$. EI-MS $\left(\mathrm{M}^{+}\right)=621.7137 \mathrm{~m} / \mathrm{z}$ (calc: 621.7141$)$.

o-Dihexyloxybenzene (5). In a $250 \mathrm{~mL}$ flask, add $5.0 \mathrm{~g}$ (45.4 mmol) of catechol and $74 \mathrm{~g}$ of $\mathrm{K}_{2} \mathrm{CO}_{3}$. Stir the suspension rapidly following the addition of $100 \mathrm{~mL} \mathrm{DMF}$ and $23.4 \mathrm{~mL}$ (167 mmol) 1-bromohexane. The reaction is heated to $90{ }^{\circ} \mathrm{C}$ and stirred for an additional $14 \mathrm{~h}$. Once cooled, excess $\mathrm{K}_{2} \mathrm{CO}_{3}$ is removed via filtration and the supernatant is placed in a vacuum distillation apparatus thereby allowing DMF solvent and unreacted 1-bromohexane to be collected by heating under reduced pressure. The remaining residue in the still-pot is redissolved in DCM $(\sim 200 \mathrm{~mL})$. The crude product is washed three times with aqueous $10 \mathrm{wt} \% \mathrm{NaOH}$, dried with $\mathrm{MgSO}_{4}$ and the solvent was removed by rotovap. The product was sufficiently pure to use in the following step. Yield is $4.4 \mathrm{~g}$ or $69 \% .{ }^{1} \mathrm{H}-\mathrm{NMR}\left(\mathrm{CD}_{2} \mathrm{Cl}_{2}, 400 \mathrm{MHz}\right)(\mathrm{ppm}): 6.87\left(\mathrm{H}_{\mathrm{A}}, \mathrm{H}_{\mathrm{B}}, \mathrm{s}\right.$, $4 \mathrm{H}), 3.98\left(-\mathrm{OCH}_{2}-, \mathrm{t}, 4 \mathrm{H}\right), 1.81-1.34\left(-\mathrm{OCH}_{2}-C_{5} H_{11}, \mathrm{~m}, 22 \mathrm{H}\right)$ ${ }^{13} \mathrm{C}-\mathrm{NMR}$ ( $\left.\mathrm{CD}_{2} \mathrm{Cl}_{2}, 400 \mathrm{MHz}\right)(\mathrm{ppm}): 149.31$ (C1), 121.02 (C2), 114.14 (C3), 69.19 (C4), 31.58 (C5), 29.34 (C6), 25.69 (C7), 22.66 (C8), 14.10 (C9). EI-MS $\left(\mathrm{M}^{+}\right)=602.08645 \mathrm{~m} / \mathrm{z}$ (calc: 602.08513). EI-MS $\left(\mathrm{M}^{+}\right)=278.2246 \mathrm{~m} / z$ (calc: 278.2239$)$.

1-Iodo-3,4-dihexyloxybenzene (6). $3.6 \mathrm{~g}$ (12.93 mmol) of (5) produced in the previous step is added to a $250 \mathrm{~mL}$ flask. $130 \mathrm{~mL}$ of $\mathrm{H}_{2} \mathrm{O}$ is added and a medium rate of stirring is initiated. $3.3 \mathrm{~g}(12.93 \mathrm{mmol})$ of finely ground $\mathrm{I}_{2}$ is added to the flask. The reaction was heated to $50{ }^{\circ} \mathrm{C} .1 .5 \mathrm{~g}(\sim 1.5 \mathrm{~mL})$ of $30 \mathrm{wt} \% \mathrm{H}_{2} \mathrm{O}_{2}$ is added with continued stirring followed by $2 \mathrm{~mL}$ of conc. $\mathrm{H}_{2} \mathrm{SO}_{4}$. The reaction was stirred vigorously for $12 \mathrm{~h}$ at $50{ }^{\circ} \mathrm{C}$. Once cooled to room temperature, the reaction solution was extracted $(\times 3)$ with $20 \mathrm{~mL}$ chloroform. The separated organic phase was washed with aqueous $10 \mathrm{wt} \% \mathrm{NaOH}$, dried with $\mathrm{MgSO}_{4}$ and the chloroform was removed by rotovap. The residue was placed in a short path micro vacuum distillation apparatus equipped with three receiving flasks. Three fractions are collected during the distillation. A low temperature fraction of residual solvent is collected first (if at all). A mid-temperature fraction $\left(135{ }^{\circ} \mathrm{C}\right.$ at $\left.60 \mathrm{mTorr}\right)$ is usually collected in small volumes and consists largely of unreacted starting material (5). At a bath temperature of $200{ }^{\circ} \mathrm{C}$, the highest fraction of reddish-brown oil is pure (6). Yield is $4.1 \mathrm{~g}$ or 78\%. ${ }^{1} \mathrm{H}-\mathrm{NMR}\left(\mathrm{CD}_{2} \mathrm{Cl}_{2}, 400 \mathrm{MHz}\right)(\mathrm{ppm}): 7.15\left(\mathrm{H}_{\mathrm{B}}, \mathrm{d}, 1 \mathrm{H}\right), 7.12$ $\left(\mathrm{H}_{\mathrm{A}}, \mathrm{s}, 1 \mathrm{H}\right), 6.59\left(\mathrm{H}_{\mathrm{C}}, \mathrm{d}, 1 \mathrm{H}\right), 3.92\left(-\mathrm{OCH}_{2}-, \mathrm{t}, 4 \mathrm{H}\right), 1.77-0.90$ $\left(-\mathrm{OCH}_{2}-\mathrm{C}_{5} \mathrm{H}_{11}, \quad \mathrm{~m}, \quad 22 \mathrm{H}\right) .{ }^{13} \mathrm{C}-\mathrm{NMR} \quad\left(\mathrm{CD}_{2} \mathrm{Cl}_{2}, 400 \mathrm{MHz}\right)$ (ppm): 150.14 (C1), 149.31 (C6), 129.86 (C2), 122.54 (C3), 115.72 (C4), 82.60 (C5), 69.43 (C7), 31.64 (C8), 29.23 (C9), 25.68 
(C10), 22.62 (C11), 14.10 (C12). EI-MS $\left(\mathrm{M}^{+}\right)=404.1212 \mathrm{~m} / \mathrm{z}$ (calc: 404.1235).

2,2'-Diiodo-4,4',5,5'-tetrahexyloxy-1,1'-biphenyl (7). $7.0 \quad \mathrm{~g}$ $(17.3 \mathrm{mmol})$ of $(6)$ is added into a $250 \mathrm{~mL}$ schlenk flask with $85 \mathrm{~mL}$ of freshly distilled DCM. The solution was cooled to $-78{ }^{\circ} \mathrm{C}$ using an acetone/dry-ice bath. Once chilled, $2.1 \mathrm{~mL}$ (17.3 mmol) of $\mathrm{BF}_{3}-\mathrm{Et}_{2} \mathrm{O}$ was added dropwise by syringe. In a separate $50 \mathrm{~mL}$ schlenk flask, $3.72 \mathrm{~g}$ (8.65 mmol) of phenyliodine bis(trifluoroacetate) (PIFA) was dissolved in a minimum amount of DCM $(\sim 30 \mathrm{~mL})$. The PIFA solution was added dropwise to the solution of (6) over the course of 5 minutes. Allow the reaction to stir for $3 \mathrm{~h}$ and slowly warm to room temperature. The reaction was quenched with $\mathrm{H}_{2} \mathrm{O}$ and the solution extracted with chloroform, dried with $\mathrm{MgSO}_{4}$ and rotovapped to dryness. The solid product was crystallized from hexanes ( $\sim 75 \mathrm{~mL}$ ) after chilling to $-20{ }^{\circ} \mathrm{C}$ over night. The yield of the first crystallization was $4.6 \mathrm{~g}$ or $65 \%$. A second batch of crystals yielded an additional $1.2 \mathrm{~g}$ bringing the total yield to $83 \%$. ${ }^{1} \mathrm{H}-\mathrm{NMR}\left(\mathrm{CD}_{2} \mathrm{Cl}_{2}, 400 \mathrm{MHz}\right)(\mathrm{ppm}): 7.30\left(\mathrm{H}_{\mathrm{A}}, \mathrm{s}, 2 \mathrm{H}\right), 6.71\left(\mathrm{H}_{\mathrm{B}}\right.$, $\mathrm{s}, 2 \mathrm{H}), 4.00\left(-\mathrm{OCH}_{2}-, \mathrm{t}, 8 \mathrm{H}\right), 1.82-0.89\left(-\mathrm{OCH}_{2}-C_{5} H_{11}, \mathrm{~m}\right.$, $44 \mathrm{H}) \cdot{ }^{13} \mathrm{C}-\mathrm{NMR}\left(\mathrm{CD}_{2} \mathrm{Cl}_{2}, 400 \mathrm{MHz}\right)(\mathrm{ppm}): 149.16$ (C1), 148.92 (C2), 141.49 (C4), 122.82 (C6), 115.50 (C3), 88.20 (C5), 69.32 (C7), 31.57 (C9), 29.17 (C8), 25.55 (C11), 22.66 (C10), 14.01 (12). EI-MS $\left(\mathbf{M}^{+}\right)=806.2256 \mathrm{~m} / z$ (calc: 806.2268$)$.

\section{2,3,6,7-Tetrahexyloxy-9,9-dichlorosilafluorene}

(9). $6.0 \mathrm{~g}$ (7.4 mmol) of (7) was added to a $100 \mathrm{~mL}$ schlenk flask and dissolved in $70 \mathrm{~mL}$ of freshly distilled THF. The reaction was subsequently cooled to $-78{ }^{\circ} \mathrm{C}$ using an acetone/dry-ice bath and $9.23 \mathrm{~mL}(14.86 \mathrm{mmol})$ of $1.6 \mathrm{M} n$-BuLi is added dropwise over $10 \mathrm{~min}$. Caution must be taken to ensure sufficient stirring is possible when a thick slurry forms after half the $n$-BuLi addition is complete and the concentration of the largely insoluble monolithiated intermediate is highest. The reaction is stirred at reduced temperature for $30 \mathrm{~min}$. In a separate $250 \mathrm{~mL}$ schlenk flask, $3.9 \mathrm{~mL}(33.88 \mathrm{mmol})$ of $\mathrm{SiCl}_{4}$ is dissolved in $35 \mathrm{~mL}$ of dry THF and chilled to $-78^{\circ} \mathrm{C}$. The chilled lithiation solution is transferred rapidly via cannula into the $\mathrm{SiCl}_{4}$ solution with rapid stirring. The react is allowed to warm to room temperature and stirred for $12 \mathrm{~h}$. Solvent and residual $\mathrm{SiCl}_{4}$ are removed in vacuo using a vacuum manifold. The residue is redissolved in pentanes and filtered through a plug of celite to remove insoluble salts. The solution is chilled at $-20{ }^{\circ} \mathrm{C}$ overnight and the supernatant removed from the insoluble by-products. Removing the pentanes yields the final product as a clear transparent oil in $71 \%$ yield or $3.4 \mathrm{~g}$. ${ }^{1} \mathrm{H}-\mathrm{NMR}\left(\mathrm{CD}_{2} \mathrm{Cl}_{2}, 400 \mathrm{MHz}\right)(\mathrm{ppm}): 7.28\left(\mathrm{H}_{\mathrm{A}}, \mathrm{s}, 2 \mathrm{H}\right), 7.21$ $\left(\mathrm{H}_{\mathrm{B}}, \mathrm{s}, 2 \mathrm{H}\right), 3.81\left(-\mathrm{OCH}_{2}-, \mathrm{t}, 4 \mathrm{H}\right), 3.59\left(-\mathrm{OCH}_{2}-, \mathrm{t}, 4 \mathrm{H}\right)$, 1.66-0.89 $\left(-\mathrm{OCH}_{2}-\mathrm{C}_{5} \mathrm{H}_{11}, \quad \mathrm{~m}, \quad 44 \mathrm{H}\right) .{ }^{13} \mathrm{C}-\mathrm{NMR} \quad\left(\mathrm{CD}_{2} \mathrm{Cl}_{2}\right.$, $400 \mathrm{MHz}$ ) (ppm): 144.61 (C1), 143.92 (C2) 138.03 (C4), 120.33 (C5), 111.13 (C6), 86.86 (C3), 68.45 (C7), 31.51 (C9), 29.24 (C8), 25.64 (C11), 22.66 (C10), 14.29 (C12). ${ }^{29} \mathrm{Si}-\mathrm{NMR}\left(\mathrm{CD}_{2} \mathrm{Cl}_{2}\right.$, $400 \mathrm{MHz})$ (ppm): 5.84 .

2.7-Dibromo-3.6-dimethoxy-2', 3', 6', ,'-tetrahexyloxy-9,9-spiro9-silabifluorene, HSSF, (10). Selective lithiation of the iodide substituents in (3) is achieved at low temperature by use of $-110{ }^{\circ} \mathrm{C} \mathrm{MeOH} / \mathrm{N}_{2}$ slush bath. $4.62 \mathrm{~g}$ (7.4 mmol) (3) is added to a $250 \mathrm{~mL}$ schlenk flask and dissolved in $70 \mathrm{~mL}$ dry THF under Ar. The solution is cooled to $-110{ }^{\circ} \mathrm{C}$ and $9.32 \mathrm{~mL}$ (14.9 mmol) $n$-BuLi (1.6 M in hexanes) is added dropwise over $30 \mathrm{~min}$. It should be noted that over the course of the lithiation, a yellow, insoluble monolithiated intermediate forms and an appropriately large stir bar is required to agitate the thick slurry. Continued addition of $n$-BuLi redissolves the intermediate and the clear solution is stirred for an additional $30 \mathrm{~min}$ at reduced temperature. In a separate schlenk flask, dissolve $4.8 \mathrm{~g}$ (7.4 mmol) of (9) in a minimum amount of dry THF. Add this solution via syringe to the solution of lithiated (3) and allow the flask to warm to room temperature and stir for $12 \mathrm{~h}$. The reaction is quenched by the addition of $\mathrm{H}_{2} \mathrm{O}$ and the product is extracted with ether. The organic phase is washed with brine and dried with $\mathrm{MgSO}_{4}$ before solvent removal by rotoevaporation. Pure blocky white crystals of (10) are obtained by crystallizing the crude powder from pentanes overnight at $-20{ }^{\circ} \mathrm{C}$. Yield is $3.6 \mathrm{~g}$ or $51 \%$ following crystallization. ${ }^{1} \mathrm{H}-\mathrm{NMR}$ $\left(\mathrm{CD}_{2} \mathrm{Cl}_{2}, 400 \mathrm{MHz}\right)(\mathrm{ppm}): 7.55\left(\mathrm{H}_{\mathrm{A}}, \mathrm{s}, 2 \mathrm{H}\right), 7.47\left(\mathrm{H}_{\mathrm{D}}, \mathrm{s}, 2 \mathrm{H}\right)$, $7.33\left(\mathrm{H}_{\mathrm{B}}, \mathrm{s}, 2 \mathrm{H}\right), 6.83\left(\mathrm{H}_{\mathrm{C}}, \mathrm{s}, 2 \mathrm{H}\right), 4.17\left(-\mathrm{OCH}_{2}-, \mathrm{t}, 4 \mathrm{H}\right), 4.11$ $\left(-\mathrm{OCH}_{3}, \mathrm{~s}, 6 \mathrm{H}\right), 3.88\left(-\mathrm{OCH}_{2}-, \mathrm{t}, 4 \mathrm{H}\right), 1.9-0.91\left(-\mathrm{OCH}_{2}-\mathrm{C}_{5} \mathrm{H}_{11}\right.$, $\mathrm{m}, 44 \mathrm{H}) .{ }^{13} \mathrm{C}-\mathrm{NMR}\left(\mathrm{CD}_{2} \mathrm{Cl}_{2}, 400 \mathrm{MHz}\right)(\mathrm{ppm}): 158.91$ (C10), 152.81 (C1), 150.73 (C2), 149.43 (C12), 144.51 (C8), 138.66 (C5), 127.12 (C7), 122.71 (C4), 118.82 (C3), 112.58 (C11), 107.13 (C6), 105.47 (C9), 69.75 (13), $56.78\left(-\mathrm{OCH}_{3}\right), 31.87$ (C16), 29.78 (C14), 26.16 (C15), 23.05 (C17), 14.21 (C18). ${ }^{29} \mathrm{Si}-\mathrm{NMR}\left(\mathrm{CD}_{2} \mathrm{Cl}_{2}\right.$, $400 \mathrm{MHz})(\mathrm{ppm}):-8.59$. EI-MS $\left(\mathrm{M}^{+}\right)=948.3000 \mathrm{~m} / \mathrm{z}$ (calc: 948.2995).

\section{Polymer synthesis}

Preparation of diarylmagnesates (12), $\mathrm{HSSF}_{2} \mathrm{Mg}$, and (11), $\mathbf{D H S F}_{2} \mathbf{M g}$. The following procedure is equally applicable to both HSSF and DHSF and is carried out in separate reaction flasks prior to polymerization. For example, the room temperature Grignard metathesis of 2.7-dibromo-3.6-dimethoxy2',3',6',7'-tetrahexyloxy-9,9-spiro-9-silabifluorene, HSSF (10), was performed in a $\mathrm{N}_{2}$ filled glovebox within a $5 \mathrm{~mL}$ scintillation vial. A 0.5 M solution of (10) was prepared using THF as a solvent. Additionally, a Grignard solution of isopropyl magnesium chloride (1.3 $\mathrm{M}$ in THF) activated by 1.0 equivalence of LiCl was prepared and used following $1 \mathrm{~h}$ of stirring to allow for the complete dissolution of the salt. The Grignard solution could be stored and used for several days in the glovebox without appreciable change. In a typical experiment, $2.0 \mathrm{~mL}$ $(1.0 \mathrm{mmol}$ ) of a $0.5 \mathrm{M}$ solution of (10) is diluted with $1.2 \mathrm{~mL}$ 1,4-dioxane and stirred rapidly. $510 \mu \mathrm{L}$ of $1.3 \mathrm{M}$ iPrMgCl-LiCl ( $0.66 \mathrm{mmol})$ was added by a single injection. The formation of insoluble white $\mathrm{MgCl}_{2}$-diox adduct is observed almost immediately. The solution is stirred continuously for $2 \mathrm{~h}$ to complete the in situ generation of diarylmagnesate (12). The white $\mathrm{MgCl}_{2}$-diox precipitate is allowed to settle, and the clear pale yellow solution is separated. The solution can be stored for several hours, but slowly decomposes over a period of $24 \mathrm{~h}$.

Poly(3,6-dimethoxy-9.9'-dihexylsilafluorene-co-3.6-dimethoxy2',3',6',7'-tetrahexyloxy-9,9-spiro-9-silabifluorene) (PDHSF-coPHSSF) (13). A monomer feed ratio $\mathbf{r}=\left[\mathbf{H S S F}_{2} \mathbf{M g}\right] /\left[\mathrm{DHSF}_{2} \mathbf{M g}\right]$ 
of unity was achieved in the copolymerization. To accomplish this, $1.0 \mathrm{~mL}$ of $\mathrm{DHSF}_{2} \mathrm{Mg}$ (11) solution (prepared as above) was added to $1.0 \mathrm{~mL}$ of the above prepared solution of $\mathrm{HSSF}_{2} \mathrm{Mg}$ (12), where $\left[\mathrm{HSSF}_{2} \mathrm{Mg}\right]=88 \mathrm{mM}$. Polymerization is initiated by adding $1 \mathrm{mg}$ or approximately $1 \mathrm{~mol} \%$ dppeNiCl $\mathrm{N}_{2}$. The solution immediately becomes yellow-orange and is stirred continuously for $15-20 \mathrm{~m}$. As the polymerization progresses, additional $\mathrm{MgBr}_{2}$-diox precipitate is formed and the solution becomes steadily more opaque and viscous. The vial is removed from the glovebox and the polymerization quenched by adding several drops of $5.0 \mathrm{M} \mathrm{HCl}$ followed by adding the solution dropwise to a large excess of methanol such that product precipitates as a fibrous white solid. Polymer is collected by suction filtration. For removal of residual monomer and oligomers, the crude polymer was soxhlet extracted with ethanol for $4-5 \mathrm{~h}$. The polymer solid is characterized by GPC and ${ }^{1} \mathrm{H}$-NMR. Optical properties where studied by collecting solution and solid state absorption and fluorescence spectra in addition to absolute quantum yield (see Fig. 3c). The yield of purified polymer is $76 \%$. ${ }^{1} \mathrm{H}-\mathrm{NMR}\left(\mathrm{CD}_{2} \mathrm{Cl}_{2}, 400 \mathrm{MHz}\right)(\mathrm{ppm})$ : 7.4-7.0 (m, 4H, DHSF repeat unit), 7.4-6.6 (m, 8H, HSSF repeat unit), 4.2-3.6 $\left(-\mathrm{OCH}_{3},-\mathrm{OCH}_{2}-, \mathrm{m}, 20 \mathrm{H}\right), 2.0-1.0(\mathrm{~m}$, $58 \mathrm{H}), 0.9-0.5\left(-\mathrm{CH}_{3}, \mathrm{~m}, 20 \mathrm{H}\right) . \mathrm{GPC}: 53 \mathrm{~kg} \mathrm{~mol}{ }^{-1}, \mathrm{PDI}=1.8$. ${ }^{1} \mathrm{H}^{-29} \mathrm{Si}-\mathrm{NMR}$ HMBC $\left(\mathrm{CDCl}_{3}, 600 \mathrm{MHz}\right)(\mathrm{ppm})$ : -8.7 (HSSF repeat unit coupled with neighbouring $7.3 \mathrm{ppm} \mathrm{H}_{\mathrm{E}}$ and 6.8 ppm $\mathrm{H}_{\mathrm{D}}$ ), 1.5 (DHSF repeat unit coupled with neighbouring $7.6 \mathrm{ppm} \mathrm{H}_{\mathrm{B}}$ ). Summing the signal intensity of the both ${ }^{29} \mathrm{Si}$ HMBC peaks and integrating provide a rough monomer ratio of $1: 0.7$ (DHSF : HSSF) (see ESI S1.9.0-S1.9.2†). ${ }^{1} \mathrm{H} /{ }^{13} \mathrm{C}$ NMR and assignments for the DHSF monomer is presented in Fig. S1.8.0-S1.8.2 in the ESI. $\dagger{ }^{1} \mathrm{H}$ NMR data is also provided for the PDHSF homopolymer for comparison.

\section{Electroluminescent device fabrication}

OLEDs were prepared using prepatterned ITO substrates (7 ohm sq ${ }^{-1}$, Visiontek Inc.) which were cleaned using $\mathrm{O} 2$ plasma for a period of $5 \mathrm{~min}$. PEDOT:PSS (AL4083, Clevios) was diluted $(1: 1 \mathrm{v} / \mathrm{v})$ with DI water prior to spin casting at $3000 \mathrm{rpm}$ for $2 \mathrm{~min}$ (acceleration was set to $1000 \mathrm{rpm} \mathrm{s}^{-1}$ ). The substrates were transferred to a $\mathrm{N}_{2}$ filled glovebox and dried by heating at $110{ }^{\circ} \mathrm{C}$ for $30 \mathrm{~min}$ on a hotplate. All subsequent processing was done under $\mathrm{N}_{2}$. Once cooled, a hole injection layer (HIL) was deposited by spin casting a $10 \mathrm{mg} \mathrm{mL}{ }^{-1}$ chlorobenzene poly-TPD (American Dye Source) solution at $2000 \mathrm{rpm}$ for 2 min (acceleration $=1000 \mathrm{rpm} \mathrm{s}^{-1}$ ). The HIL layer was dried by baking the substrate at $150{ }^{\circ} \mathrm{C}$ for $30 \mathrm{~min}$. Once cooled, the emissive polymer layer (either (PHSSF-co-PDHSF) or (PDHSF)) was deposited by spincasting an $10 \mathrm{mg} \mathrm{mL}^{-1}$ toluene solution at $1000 \mathrm{rpm}$ for $2 \mathrm{~min}$ (acceleration $=1000 \mathrm{rpm} \mathrm{s}^{-1}$ ). The substrate was placed in the glovebox antechamber and dried under vacuum for a period of $30 \mathrm{~min}$ prior to depositing a $\mathrm{Ca} /$ $\mathrm{Al}$ cathode. The optimal Ca layer thickness was $50 \mathrm{~nm}$ (deposited at a rate of $0.8 \AA \mathrm{s}^{-1}$ ). The $\mathrm{Al}$ layer thickness was $200 \mathrm{~nm}$ (deposited at a rate of $1 \AA^{-1} \mathrm{~s}^{-1}$ ). $I-V-L$ device characteristics were measured following the encapsulation of the OLEDs to protect them from degradation. Radiance of each pixel (as a function of applied bias) was measured using a Keithley 2400 SourceMeter and a calibrated integrating sphere coupled to a fiber spectrometer.

\section{Acknowledgements}

GAO is Government of Canada Research Chair in Materials Chemistry and Nanochemistry. JM is an NSERC Graduate Fellow. Both are deeply indebted to the Natural Sciences and Engineering Research Council for strong and sustained support of their work.

\section{Notes and references}

1 P. I. Saragi, T. Spehr, A. Siebert, T. Fuhrmann-Lieker and J. Salbeck, Chem. Rev., 2007, 107, 1011.

2 R. Pudzich, T. Fuhrmann-Lieker and J. Salbeck, Adv. Polym. Sci., 2006, 199, 83.

3 J. Pei, J. Ni, X. H. Zhou, X. Y. Cao and Y. H. Lai, J. Org. Chem., 2002, 67, 8104.

4 U. Mitschke and P. J. Bauerle, J. Chem. Soc., Perkin Trans. 1, 2001, 740.

5 C. Adachi, T. Tsutsui and S. Saito, Appl. Phys. Lett., 1989, 55, 1489.

6 H. Spreitzer, H. Schenk, J. Salbeck, F. Weissortel, H. Riel and W. Riess, Proc. SPIE-Int. Soc. Opt. Eng., 1999, 3797, 316.

7 J. Y. Shen, C. Y. Lee, T. H. Huang, J. T. Lin, Y. T. Tao, C. H. Chien and C. Tsai, J. Mater. Chem., 2005, 15, 2455.

8 M. Pfeiffer, K. Leo, X. Zhou, J. S. Hunag, M. Hofmann, A. Werner and J. Blochwitz-Nimoth, Org. Electron., 2003, 4, 89.

9 H. S. Chen, F. I. Wu, C. F. Shu, C. H. Chien and Y. T. Tao, J. Mater. Chem., 2004, 14, 1585.

10 T. P. I. Saragi, R. Pudzich, T. Fuhrmann and J. Salbeck, Appl. Phys. Lett., 2004, 84, 2334.

11 T. P. I. Saragi, R. Pudzich, T. Fuhrmann-Lieker and J. Salbeck, Opt. Mater., 2007, 29, 879.

12 D. Schneider, T. Rabe, T. Riedl, T. Dobbertin, M. Kroeger, E. Becker, H. H. Johannes, W. Kowalsky, T. Weimann, J. Wang and P. Hinze, Appl. Phys. Lett., 2004, 85, 1659.

13 D. Schneider, T. Rabe, T. Riedl, T. Dobbertin, O. Werner, M. Kroger, E. Becker, H. H. Johannes, W. Kowalsky, T. Weimann, J. Wang, P. Hinze, A. Gerhard, P. Stossel and H. Vestweber, Appl. Phys. Lett., 2004, 84, 4693.

14 D. Schneider, T. Rabe, T. Riedl, T. Dobbertin, M. Kroger, E. Becker, H. H. Johannes, W. Kowalsky, T. Weimann, J. Wang and P. Hinze, J. Appl. Phys., 2005, 98, 043104.

15 N. Johansson, J. Salbeck, J. Bauer, F. Weissortel, P. Broms, A. Andersson and W. R. Salaneck, Adv. Mater., 1998, 10, 1136.

16 T. P. I. Saragi, T. Fuhrmann-Lieker and J. Salbeck, Adv. Funct. Mater., 2006, 16, 966.

17 T. P. I. Saragi, T. Fuhrmann-Lieker and J. Salbeck, Synth. Met., 2005, 148, 267. 
18 C. Hosokawa, H. Higashi, H. Nakamura and T. Kusumoto, Appl. Phys. Lett., 1995, 67, 3853.

19 T. Spehr, R. Pudzich, T. Fuhrmann and J. Salbeck, Org. Electron., 2003, 4, 61.

20 J. Salbeck, N. Yu, J. Bauer, F. Weissortel and H. Bestgen, Synth. Met., 1997, 91, 209.

21 J. Salbeck, F. Weissoertel and J. Bauer, Macromol. Symp., 1997, 125, 121.

22 H. Lee, J. Oh, H. Y. Chu, J. I. Lee, S. H. Kim, Y. S. Yang, G. H. Kim, L. M. Do, T. Zyung, J. Lee and Y. Park, Tetrahedron, 2003, 59, 2773.

23 S. Tao, Z. Peng, X. Zhang, P. Wang, C. S. Lee and S. T. Lee, Adv. Funct. Mater., 2005, 15, 1716.

24 J. P. Choi, K. T. Wong, Y. M. Chen, J. K. Yu, P. T. Chou and A. J. Bard, J. Phys. Chem. B, 2003, 107, 14407.

25 C. C. Wu, Y. T. Lin, H. H. Chiang, T. Y. Cho, C. W. Chen, K. T. Wong, Y. L. Liao, G. H. Lee and S. M. Peng, Appl. Phys. Lett., 2002, 81, 577.

26 F. Fungo, K. T. Wong, S. Y. Ku, Y. Y. Hung and A. J. Bard, J. Phys. Chem. B, 2005, 109, 3984.

27 K. T. Wong, S. Y. Ku, Y. M. Cheng, X. Y. Lin, Y. Y. Hung, S. C. Pu, P. T. Chou, G. H. Lee and S. M. Peng, J. Org. Chem., 2006, 71, 456.

28 J. Salbeck, M. Schorner and T. Fuhrmann, Thin Solid Films, 2002, 417, 20.

29 T. Spehr, A. Siebert, T. Fuhrmann-Lieker, S. Salbeck, T. Rabe, T. Riedl, H. H. Johannes, W. Kowalsky, J. Wang, T. Weimann and P. Hinze, Appl. Phys. Lett., 2005, 87, 161103.

30 R. Pudzich and J. Salbeck, Synth. Met., 2003, 138, 21.

31 U. Lemmer, S. Heun, R. F. Mahrt, U. Scherf, M. Hopmeier, U. Siegner, E. O. Goebel, K. Muellen and H. Bässler, Chem. Phys. Lett., 1995, 240, 373.

32 M. Grell, D. D. C. Bradley, G. Ungar, J. Hill and K. S. Whitehead, Macromolecules, 1999, 32, 5810.

33 U. Bach, D. Lupo, P. Comte, J. E. Moser, F. Weissortel, J. Salbeck, H. Spreitzer and M. Gratazel, Nature, 1998, 395, 583.

34 U. Bach, Y. Tachibana, J. E. Moser, S. A. Haque, J. R. Durrant, M. Gratzel and D. R. Klug, J. Am. Chem. Soc., 1999, 121, 7445.

35 K. Tamao, M. Uchida, T. Izumizawa, K. Furukawa and S. Yamaguchi, J. Am. Chem. Soc., 1996, 118, 11974.

36 S. Yamaguchi, T. Endo, M. Uchida, T. Izumizawa, K. Furukawa and K. Tamao, Chem. - Eur. J., 2000, 6, 1683.

37 N. J. Watkins, A. J. Makinen, Y. Gao, M. Uchida and Z. H. Kafafi, Proc. SPIE Int. Soc. Opt. Eng., 2004, 5214, 368.

38 L. C. Palilis, H. Murata, M. Uchida and Z. H. Kafafi, Org. Electron, 2003, 4, 113.
39 M. Uchida, T. Izumizawa, T. Nakano, S. Yamaguchi, K. Tamao and K. Furukawa, Chem. Mater., 2001, 13, 2680.

40 H. Murata, G. G. Malliaras, M. Uchida, Y. Shen and Z. H. Kafafi, Chem. Phys. Lett., 2001, 339, 161.

41 L. C. Palilis, M. Uchida and Z. H. Kafafi, IEEE J. Sel. Top. Quantum Electron., 2004, 10, 79.

42 H. Gilman and R. D. Gorsich, J. Am. Chem. Soc., 1958, 80, 1883.

43 L. S. Chang and J. Y. Corey, Organometallics, 1989, 8, 1885.

44 B. H. Boo, J. Park, H. G. Yeo, S. Y. Lee, C. J. Park and J. H. Kim, J. Phys. Chem. A, 1998, 102, 1139.

45 D. Ballweg, Y. Liu, I. A. Guzei and R. West, Silicon Chem., 2002, 1, 57.

46 C. W. Keyworth, K. L. Chan, J. G. Labram, T. D. Anthopoulos, S. E. Watkins, M. McKiernan, A. J. P. White, A. B. Holmes and C. K. Williams, J. Mater. Chem., 2011, 21, 11800.

47 I. B. Berlman, J. Chem. Phys., 1970, 52, 5616.

48 S. Lee, B. Jang and Z. Kafafi, J. Am. Chem. Soc., 2005, 127, 9071.

49 J. Chen, C. C. W. Law, J. W. Y. Lam, Y. Dong, S. M. F. Lo, I. D. Williams, D. Zhu and B. Z. Tang, Chem. Mater., 2003, 15, 1535.

50 L. C. Palilis, A. J. Makinen, M. Uchida and Z. H. Kafafi, Appl. Phys. Lett., 2003, 82, 2209.

51 H. Murata, Z. H. Kafafi and M. Uchida, Appl. Phys. Lett., 2002, 80, 189.

52 J. McDowell, I. Schick, A. Price, D. Faulkner and G. Ozin, Macromolecules, 2013, 46, 6794.

53 T. Dohi, M. Ito, K. Morimoto, M. Iwata and Y. Kita, Angew. Chem., Int. Ed., 2008, 47, 1301.

54 Y. Kita, K. Morimoto, M. Ito, C. Ogawa, A. Goto and T. Dohi, J. Am. Chem. Soc., 2009, 131, 1668.

55 W. W. H. Wong, J. Hooper and A. B. Holmes, Aust. J. Chem., 2009, 62, 393.

56 K. L. Chan, M. J. McKiernan, C. R. Towns and A. B. Holmes, J. Am. Chem. Soc., 2005, 127, 7662.

57 K. L. Chan, S. E. Watkins, C. S. K. Mak, M. J. McKiernan, C. R. Towns, S. I. Pascu and A. B. Holmes, Chem. Commun., 2005, 5766.

58 J. McDowell, F. Flaig-Maier, T. J. A. Wolf, A.-N. Unterreiner, U. Lemmer and G. Ozin, ACS Appl. Mater. Interfaces, 2014, 6, 83.

59 J. C. deMello, H. F. Wittmann and R. H. Friend, Adv. Mater., 1997, 9, 230.

60 R.-F. Chen, Q.-L. Fan, C. Zheng and W. Huang, Org. Lett., 2006, 8, 203.

61 A. I. Vogel, A. R. Tatchell, B. S. Furnis, A. J. Hannaford and P. W. G. Smith, Vogel's Textbook of Practical Organic Chemistry, Prentice Hall, NY, 5th edn, 1996. 